\title{
RETRACTED ARTICLE: Transcriptome profile alterations in asthenozoospermic and idiopathic infertile spermatozoa uncovered by microarray
}

\author{
Madhukar Shivajirao Dama • \\ Mohammad Kaleem Ahmad • Nishi Gupta • \\ Saraswati Gupta • Satyanarayan Sankhwar • \\ Abbas Ali Mahdi • Archana David • Geeta Khanna • \\ Anil Khanna - Singh Rajender
}

Received: 4 September 2012 / Accepted: 19 November 2012 /Published online: 18 December 2012

(C) Springer Science+Business Media New York 2012

This article has been retracted at the request of the Editor-inChief. The original submission was made without the approval of the previously listed co-author Dr. Rajender Singh. In addition, the article is being retracted because the corresponding author is not the owner of the data and has no right to publication.

This article has been retracted at the request of the Editor-in-Chief. The original submission was made without the approval of the previously listed co-author Dr. Rajender Singh. In addition, the article is being retracted because the corresponding author is not the owner of the data and has no right to publication.

M. S. Dama $\cdot$ N. Gupta $\cdot$ S. Rajender $(\varangle)$

Division of Endocrinology, Central Drug Research Institute (Council of Scientific and Industrial Research), Lucknow,

Uttar Pradesh, India

e-mail: rajendar_singh@cdri.res.in

M. S. Dama

e-mail: madhukar262@gmail.com

M. K. Ahmad • A. A. Mahdi

Department of Biochemistry, Chhatrapati Shahuji Maharaj

Medical University, Lucknow, India

S. Gupta $\cdot$ A. David $\cdot$ G. Khanna $\cdot$ A. Khanna

IVF Department, Ajanta Hospitals and IVF Centre Pvt. Ltd.,

Lucknow, Uttar Pradesh, India

S. Sankhwar

Department of Urology, Chhatrapati Shahuji Maharaj Medical

University, Lucknow, Uttar Pradesh, India 